\title{
How the construction of women in discourse explains society's challenge in accepting females commit sexual offences against children
}

\begin{tabular}{|r|l|}
\hline Journal: & Journal of Criminal Psychology \\
\hline Manuscript ID & JCP-07-2019-0024.R1 \\
\hline Manuscript Type: & Research Paper \\
\hline Keywords: & $\begin{array}{l}\text { female offenders, female sexual offenders, females who commit sexual } \\
\text { offences against children, discourse analysis, discursive psychology, } \\
\text { membership categorisation analysis }\end{array}$ \\
\hline \multicolumn{2}{|l}{} \\
\hline
\end{tabular}

\section{SCHOLARONE ${ }^{m}$ \\ Manuscripts}




\section{MANUSCRIPT DETAILS}

TITLE: How the construction of women in discourse explains societyâ $€^{\mathrm{TM}} \mathrm{s}$ challenge in accepting females commit sexual offences against children

\section{ABSTRACT:}

This paper explores the way gender and gender roles are socially constructed by those who have experience of females committing sexual offences against children.

Using a discursive approach, supported by membership category analysis (MCA), a secondary analysis of qualitative data illustrates how the social construction of gender and gender roles impacts on societyâ $\epsilon^{\mathrm{TM}} \mathrm{s}$ perception of females who commit sexual offences against children.

Discourse analysis found three patterns employed within conversation that demonstrate how the construction of women influence societyâ $€^{\mathrm{TM}} \mathrm{s}$ incomprehension of females who commit sexual offences against children: women can be trusted, women do not manipulate and groom and, women are not sexually aggressive.

The use of secondary data is a limitation of this study and may not provide the richness of detail that primary accounts of people with this lived experience may. The difficulty in accessing this subpopulation highlights the hidden nature of the topic and highlights the need for further research in this area.

CUST_PRACTICAL_IMPLICATIONS_(LIMIT_100_WORDS) :No data available.

CUST_SOCIAL_IMPLICATIONS_(LIMIT_100_WORDS) :No data available.

This is the first study to explore how gender discourse is used in discussions of females who commit sexual offences against children. The value of this exploration highlights the need of society to adjust their perceptions of the offending capabilities of women, to ensure the experiences of people who experience this form of sexual abuse are accepted. 


\section{'So unnatural it offends against all instincts': How the construction of women in discourse explains society's challenge in accepting females commit sexual offences against children}

\section{Introduction}

The results of a recent meta-analysis showed that the proportion of females who commit sexual offences is higher than first thought and evidences a need for a greater understanding of female sexual offending (Cortoni, Babchishin, and Rat, 2017). Figures estimate that the ratio of female to male sexual offenders is 1:20 (Cortini and Hanson, 2006; Cortoni, Hanson and Coache, 2010) and an average of 50-100 women are convicted of sexual offences against children in England and Wales each year (Kemshall, 2004).

In comparison to male sexual offenders, little is known about females who commit sexual offences against children (Cortoni, 2010; Denov, 2004a) and caution should be paid in applying male gendered literature to females who engage in this behaviour (Williams Gillespie, and Elliot, 2019). Literature available on female sexual offences against children suggests the offence is either non-existent or extremely rare and therefore less value is placed on unpacking this crime (Krista, 1994; Wahl, 1960). More contemporary literature repeats similar attitudes that indicate females are incapable of such abuse due to their physical and reproductive attributes (Lawson, 1991) and some even suggest sexual abuse committed by a female perpetrator may be less harmful to the victim than abuse committed by a male (Finkelhor, 1984; Tsopelas, Tsetsou, Ntounas and Douzenis 2012). Only half a 
century ago scholars asked, "what harm can be done without a penis?” (Mathis, 1972, p. 54).

This staggering misconception that sexual offences committed by females causes less harm than sexual offences by males is ill-informed. Men and women sexually abused as children by both males and females report that the abuse experienced from females had more impact on their mental and emotional health than the abuse they experienced from males (Denov, 2004b). Such misconceptions may contribute to the evidence base which suggests although sex offences committed by females account for a small proportion of reported offences, there remains a large amount of unreported sex offences committed by females (Cortoni et al., 2017). The unacceptable implication of this is there remains a cohort of people who have been sexually abused by women, but who remain hidden from support and criminal justice services, and this must be explored, challenged and improved.

One explanation for an underreporting of this offence, which this paper explores, is society's reluctance to accept that women are capable of sexually abusing children (Krug 1989; Lawson 1993). The potency of these factors is underscored by research which illustrates $78 \%$ of children state their reports of sexual abuse by a female were challenged, minimized or not acknowledged by a person in a position of power (Lawson, 1993; Denov, 2003a). Conclusions from the existing literature imply that the existence of sexual abuse by females is often denied by society due to the uncomfortable reality of its existence (Bunting, 2005; Denov, 2004a; 2004b; Krista, 1994; Mathis, 1972; Wahl, 1960). Societies social construction of gender and gender dichotomy establish expectations of acceptable 
gendered behaviour in early life, dictates that females are nurturing, protecting and nonsexual (Lorber, 1994; Toro-Morn, 2008). To accept that females can, and do, commit sexual abuse against children is to challenge the lifelong perceptions we hold about women and that can be uncomfortable to accept (Denov 2004a, 2004b).

To ensure that children's narratives of sexual abuse by females are more widely acknowledged and understood, it is crucial to understand (i) how society interprets these offences, and (ii) what barriers are in place within our cognitive processing to make testimonies that contradict our gendered stereotypes so uncomfortable to hear. The present study explores this area further by using a secondary data source to examine how gender and gender roles are socially constructed in discourse on females who commit sexual offences against children.

\section{Background}

Past stereotypes of women regard them as heterosexual, submissive, naturally maternal and monogamous beings (Wykes, 1998). Historically, women who do not conform to these gender ideals and engage in non-heterosexual relationships, work in the sex industry, or engage in relationships that are sexually non-monogamous, are treated as immoral outcasts and are liable to societal rejection (Jewkes, 2004). Stereotyping women as submissive and maternal contributes to the socially constructed idea of femininity that women are expected to fulfil and underestimates their potential to cause harm to others (Finkelhor and Russell, 1984; Hetherton 1999; Lorber, 2004). 
Evidence suggests that females are more likely than males to be victims of sexual abuse, and the perpetrators more likely to be male, fulfilling standard social gendered expectations (Lorber, 2004; Saradijian, 1996). When females sexually abuse children, they fall outside gendered expectations, and their offending behaviour is rationalised by exploring whether their offence was a result of coercion of a male abuser, rather than accepting a woman is the solo perpetrator (Williams et al., 2019). The assumptions of a male perpetrator initiating the abuse and coercing a female into abuse raises questions of gender dichotomies, and expected gendered characteristics (Toro-Morn, 2008). Socialization has placed males as the dominant sex who can show aggressive tendencies, who may lack in nurturance, and are more likely than women to engage in sexually non-monogamous relationships. Therefore, women who display unexpected characteristics that do match their gender can be met with anger, disgust and a sense of disbelief (Birch, 1993; Saradijian, 1996). Other women perceive women who demonstrate behaviour that is contrary to the expected social category of females as a threat to their group identity, are atypical of the usual group norm and completely rejected from the group identity (Lorber, 2004; Saradijian, 1996).

With the media's interest in sex crimes becoming more apparent, the media vocabulary becomes ever more influential, and contributes to a social construction of a profile of a person who commits sexual offences against children. Research has shown that the media's use of labels completely overlooks the other possibilities of perpetrators, such as women (Mayer, 1992). This then contributes to societal rejection if the reality occurs. 
The seriousness of society's refusal to accept that females are capable of such abuse is reflected in the unfamiliarity of support services for victims of sexual abuse (Bunting, 2005). Child protection services and the criminal justice system are not provided with enough adequate training or policies concerning female sexual abuse, with professionals in this area unaware of the seriousness of the issue (Bunting, 2005). There have been reports of high levels of denial and minimization within professional services, due to the issue being under-reported and attitudes towards gender categories and gender roles too deeply entrenched (Bunting, 2005; Denov, 2003a, 2003b, 2004a). Furthermore, disbelief or attempts to minimize sexual abuse by females from professionals has been shown to heighten the negative effects of the abuse experienced by the victim (Denov, 2003a). Therefore, it is crucial that we do more to understand the views held by society of female sexual offenders.

\section{The study}

The role of language plays a crucial part in society's understanding and comprehension of gender and gender roles and how socially constructed gender roles may be used to help deny or minimize abuse. Therefore, the present study aimed to identify the way individuals socially construct gender and gender roles in relation to females who commit sexual offences against children.

Due to the sensitive nature of the topic and the limited nature of access to such data at this level, secondary analysis was used to provide unique data relating to sexual offences committed by females. The analysis aimed to explore how gender discourse is used in 
discussions of females who commit sexual offences against children. Previous work highlights the under-utilized method of discursive analysis (see Edwards and Potter, 1992) within research that explores offences. This type of analysis is beneficial for exploring language use in the constructing identities in difficult circumstances. (Winder, Gough and Seymour-Smith, 2015).

\section{Methodology}

With permission, we undertook a secondary analysis from a British documentary entitled “The Ultimate Taboo" (Molloy, 1997) broadcast in the United Kingdom on BBC1 on the $6^{\text {th }}$ October 1997 and available to the public sphere. The documentary was transcribed using a modification of the Jefferson system (Atkinson and Heritage, 1984; see table 1). Interviews analysed include opinion pieces from two chartered psychologists, three adults who had been abused by their mother as children, and a mother of a child abused by another female.

$>>$ insert table $1<<$

Data analysis

The analysis was informed by discursive psychology (see Edwards and Potter, 1992). A discursive approach was taken as it provides the ability to construct reality through language and explain how society 'makes sense' of societal issues through their discourse with others (Edwards and Potter, 1992). Method of compiling accounts are constructed to provide a version of reality. 
In addition, this study employs a membership categorization analysis (MCA, Sacks, 1972). This ethnomethodological approach analyses the natural behaviour of others with the aim to understand current cultural issues (Stanley and Wise, 1993). MCA examines the interaction between others and the rules that are created during conversation. Emphasis is placed on the categories that individuals place themselves in during conversation (Sacks, 1992). MCA is an essential device for examining how we construct gender and gender roles in society through the category bound activities (CBA) (i.e. housework) or innate characteristics (i.e. nurturing) society assumes of women (Stokoe, 2003). MCA can highlight the moral expectations society constructs within a category (Jayusi 1984, 1991) and explain why society's construction of females and women contributes to our acceptance of this type of abuse when it occurs.

Some categories can be 'duplicately organized' and may fit within two categories (Stokoe, 2003) and females who commit sexual offences against children falls within this duplication, adopting conflicting characteristic for each identity category they hold (Silverman, 2001). For example, protector and abuser. When presented with the category Mother (Widdicombe and Wooffitt, 1995) society's expectations are opposite to that of a 'paedophile'. Therefore, when the two are presented together, membership categorization analysis (MCA) provides a compelling explanation for society's reaction towards the unconventional reality. Nilan (1995) illustrated this through the category of female and claimed that when females do not conform to the predicates of their category, they do not maintain the ideal of femininity and may be subject to prejudices. 
Research has suggested that moral reasoning is particularly used in membership categorization (Watson, 1997), where activities determine the morality of each category (Stokoe, 2003). When one makes a moral judgement about another, we can understand how social and cultural divisions are created (Lepper, 2000). Saradijian suggested in 1996 that those who do not conform, and who fall outside our expectations, create a sense of discomfort or 'cognitive dissonance' that society cannot deal with. Therefore, we search for a form of justification that will minimize the effects that pose threat to our own identity. It is therefore this constant moral categorization of $w e$ and others that re-establish cultural expectations, with limited room for change (Wowk, 1984). In this sense, MCA is imperatively useful for the study of social construction of gender through interaction (Mäkitalo and Säljö, 2002).

\section{Analysis}

Discourse analysis found three patterns within the documentary's narrative that demonstrate how the construction of women through language influence society's incomprehension of females who commit sexual offences against children. The use of gender categories and gendered expectations of character and personal values help to explain why females who commit this type of offence seems ever so more shocking. Within this data, the offence is constructed through language within assumptions that women can be trusted, women do not manipulate or groom, and women are not sexually aggressive. These three assumptions of females exacerbate the offence when it occurs and contributes to heightened negative reactions of the offence. The three inter-related patterns are now discussed in more detail and extracts from the documentary are used to support the arguments made. 


\section{Construction 1: Women can be trusted}

Sexual offences against children are categorized by manipulation, preying on the vulnerable and taking advantage of the helpless. In contrast, females are categorized by protecting children from harm. These extracts demonstrate feelings of broken trust from a woman who was abused by her mother as a child and incomprehension that a woman who is also a mother can commit these types of offences.

300 Leah: I couldn't understand how your own hhh mother (0.8) You've got no one else to 301 turn to $>$ d'you know what I mean? < If it is your dad (.) do:ing it (.) at least you've got some 302 chance(.)You've got your mother (.) y'know to try and talk to if she's a good mother (.) 303 But when you've $\uparrow$ got your mother doing it as well (.) ((shakes head)) > wha(h)t cha(h)nce 304 have you $\uparrow$ got? $<$ No one's going to believe you

$305(1.8)$

$306{ }^{\circ}$ There is no escape ${ }^{\circ}$

Within this extract the possessive pronoun of "own" (line 300), appears to be an influential factor to the reaction of sexual abuse by females; particularly those who may be a relative or friend. Not only does the abuse create a sense of betrayal to the Leah, but betrayal to the category of woman and mother and the characteristics and values that embody these identities. Leah's statement on line 301 "you've got no one else to turn to" evidences an expectation from a child that their mother holds a duty and obligation to protect and help. Leah emphasizes the impossible situation she faced when the person who she would normally seek or expect to seek help or refuge from was her abuser. The comparison made 
between sexual abuse by a mother to the abuse by a father, suggests Leah feels that sexual abuse by a father may provide an opportunity for help, as there would be the mother to confide in and confirms the category mother as holding CBAs of protection. Leah's narrative suggests that no one would believe a mother would sexually abuse her daughter due to the CBAs of the category mother.

Regular reference to the CBAs of the categories woman and mother is demonstrated by Mary, whose son was sexually abused by another woman.

531 Mary: I'm $\mathfrak{\text { angry }}$ with her (.) I can't understand where she is coming from when she is 532 doing this to the children. hhh I $\uparrow$ can't believe uh um $>$ as a mother $<$ I trusted $\uparrow$ her and I 533 can't be:lie:ve that a woman would let people trust her and then go on to misuse that $\downarrow$ trust

The membership category of mother ">as a mother $<$ I trusted $\uparrow$ her" (Line 533) displays the trust that Mary placed in another woman due to the CBAs that she held due to the categories of woman and mother. These expected CBA's of the category woman are further reinforced on lines 534-535 “I ca:n’t be:lie:ve that a woman would let people trust her and then go on to misuse that $\downarrow$ trust". Mary's frequent use of gendered pronouns throughout this extract "her" (line 531) and "she" (line 532) emphasize the offenders' gender and displays Mary's disbelief that a woman has committed this type of offence. This extract provides elements of category bound rights and assumed obligations a person who is a member of this category should hold. Within this extract, Mary presumes that another woman would fulfil the CBAs of the category woman and mother and care for and protect her child. In addition, due to the category of woman and mother, Mary's son would trust this woman to provide appropriate care for him whilst in her care as a minor. 
As the abused boy's mother, Mary is in the expected category of a mother and nonoffending woman, and she distances herself from the offending woman through her inability to comprehend her actions "I can't understand" (Line 531). The use of 'I' places Mary in two categories of woman and mother, demonstrating that her assessment of the situation is limited to these categories. Suggested attempts to understand why this woman abused her son are made, however due to CBAs that Mary holds as a mother and a woman this is physically beyond her comprehension "can't" (Line 531). Mary repeats this attempt a further two times "I can't" (Lines 533; 534) to emphasize her incomprehension and distance herself further from the woman who offended.

Throughout this extract, vocal emphasis is used to stress the contrast in woman and abuser and of the abuse between the child and the woman. The vocal emphasis on the category "children" (Line 532) highlights the innocence of children, which reminds the audience that it is these very women that are assumed to protect children. Mary's escalates her difficulty understanding to disbelief (Line 533) and shares her emotions through vocal emphasis (“† $\underline{\text { angry }}$ ”; line 531 ) towards the woman who abused her child; an expected response from a mother towards someone who has caused harm to their child. Mary places vocal emphasis the word "woman" (line 533) to illustrate her shock at the gender of the perpetrator and trusted person. Alternatively, Mary may not have been as shocked if the perpetrator was male.

\section{Construction 2: Women do not manipulate and groom}


The concept of grooming encompasses types of non-sexual behaviour that occur prior to physical abuse occurring. Grooming can include befriending the parents or carers of a child to gain close and sometimes unsupervised access to a child. This can be built upon predatory and manipulative conduct (Berliner, 2017). The following extract illustrates Mary's account of the female perpetrators grooming behaviour towards Mary's son.

116

117

118

119

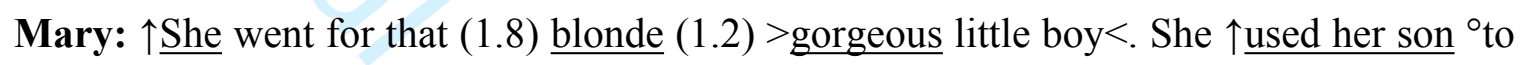
get $\underline{\text { him }}^{\circ} .<$ She used her son $>$ to get him over to ${ }^{\circ}$ play ${ }^{\circ}$. She used her son t:o .hhh $<\uparrow$ do the things $>$ that our son (0.4) liked doing. If our son li:ked certain $\uparrow$ videos she'd get $\uparrow$ her son to ${ }^{\circ}<$ like them too $>^{\circ}$.

This extract creates a scene of preying and manipulation, seeking calculated possession of the child. This is emphasized by Mary's description of her son, creating a visual image of scenic purity and innocence who is violated by a predatory and calculated monster. The repeated use of "used her son" (lines 117 and 118) suggests repeated grooming of manipulation to gain access. It also highlights the female perpetrator belongs to the category mother and the vocal emphasis suggests shock that the female perpetrator would manipulate her son to carry out a sexual offence against another child. The repeated use of "to get him" (lines 117 and 118) suggests a predatory and aggressive nature of the abuse, sharing similarities to childhood stories where a mythical monster will 'capture' innocent children. 
91 Interviewer: When did she make her first sexual approach?

$92(1.8)$

93 How did she do it?

94 Mary: Appare-n - tly not long after (0.4)<he is twelve $>$. Uh um (.) Her own (.) children 95 sh-e (0.3) sent round to (.) the local park to play (.) Our son is in the house (.) and she is 96 just doing her housework (.) $\uparrow a n:: d>a p p a r e n t l y<$ while she is cleaning the bathroom .hhh just turned around to our son and .hhh said "How would you like this?" an::d >actually abused $\uparrow$ him $<$.

100

101

102

103

She ma* $^{*}$ sturbated ${ }^{\circ}$ him $^{\circ}$ on that $>$ first occasion $<$ (.) with him $>$ apparently $<$ leaning against the door. Afterwards he just .hhh (.) $>$ cleaned himself up $<$ and she said "You'd better $\uparrow$ pop off and play with the children now (0.3) and I'll finish the $\uparrow$ housework and ${ }^{\circ}$ will see you later. ${ }^{\circ}$

Mary compares the category of woman/wife/mother with the category child sex offender. Mary uses a possessive pronoun to describe her abuser as carrying out the abuse on "her own children" and provides the information that this abuser is a mother and assumes all associated CBAs of this category. This is corroborated by Mary's description of her mother engaging in an expected characteristic of a mother sending her children to the park to play, but for the purposes of creating an opportunity to abuse another child. The stark contrast between the abuser's children playing whilst she sexually abuses another child, enhances the predatory and planned nature of the abuse.

A XY formation within the CBAs the category woman/wife presents images of the female offender carrying out domesticated tasks such as "the housework" and "cleaning the 
bathroom". Yet is soon contrasted with descriptions of the sexual assault that followed the daily household tasks. These mundane CBAs provides a sense of normality and ordinariness to Mary's son's experience of his perpetrator. The activities presented are those that society can relate to in everyday life, creating an unsettling scene and feeling of insecurity for Mary's son and society.

The use of reported speech becomes important later in the extract in its contribution to the relevance of the category of mother. The language reportedly used by the abuser of the child, is mother like jargon (Lines 103-105). For example, the gentle use of " $\uparrow$ pop off and play" (Line 104) with the added increase in tone, may be language that an adult would use to a child. This compared with the previous statement of "cleaned himself up" (Line 103) provides a contrast in CBAs for the young boy too; by firstly being involved in a sexual act, then going to the park to play. This CBA of a child playing emphasizes the child's young age. The repeated CBA of "housework" (Line 105) reminds the audience that this abuser is a woman, whilst providing stark contrast between the categories woman and child sex offender.

\section{Construction 3: Women are not sexually aggressive}

This extract demonstrate the conflicting CBAs associated with the categories woman and abuser. The category woman/mother holds CBAs such as protection and kindness, compared to that of the category sexual offender and the CBA constructed within that category such as, sexual aggression. 
289 Interviewer: Who started these sessions? Who is the dominant partner?=

290 Leah: $=$ My mother (.) my mother always came to get me ((nods head))

291 Sara: My dad is at $\uparrow$ work .hhh (.) I is (.) cleaning the bath out $>$ and everything $<$ hhh when 292 >all of a sudden my mum come in the bathroom < .hhh an:d uh um she pushed me $\downarrow$ flyin' 293 an:d (0.7) she grabbed ${ }^{\circ} \downarrow$ my hair ${ }^{\circ}$.hhh an:d uh um

\section{$294(1.7)$}

295 hhh $>$ she dragged me $<$ into the bedroom and uh um she made me do things (.) y'know (.) 296 for her satisfaction

This extract begins with the interviewer proposing a question to determine which parent initiated the abuse. The category work used in this question is particularly odd with the use of "sessions" when referring to the abuse (line 289); suggests that this is a regular, regimented routine in the child's life. The category of "partner" (line 289) provides CBAs of an equal role of abuse between mother and father, however the previous adjective of "dominant" (line 289) with the additional vocal emphasis, suggests the interviewer is trying to distinguish which parent had the most involvement.

The immediate latching from Leah suggests a definite answer of "=My mother" (Line 290) as well as the suggestion of a biological relationship rather than a loving one. The use of the possessive pronoun before mother of "My" (Line 290) provides the audience with the knowledge of whose mother and Leah's repetition of "my mother" (Line 290) confirms their relationship. The extreme case formulation of "always" (Line 290), vocal emphasis and language used, implies the regularity of the abuse by the mother only. The language 
use of "came to get me" (Line 290) appears childlike and pure, with CBAs of a creature or monster, individually targeting her, mirroring Mary’s previous extract.

Sara joins the interview and confirms her father's absence at the time of the abuse, indicating that he is not complicit in the offence and implies that he may not have been aware of the frequency of the abuse due to his absence. This is followed by mundane accounts of everyday life which add believability to the narrative (Line 291). The account is built into a XY formation (Lines 292-293) and suggests that the attacks are unprovoked which adds to the aggressive nature of the abuse.

When Sara is recalling the abuse, her speech changes and becomes particularly irregular and tentative with several prosodic changes in speed, tone, volume and regular use of discourse markers such as "uh um" (Line 292; 293) and suggest difficulty in describing such sensitive events. When describing the violent acts, Sara uses a list of three to describe three separate acts of violence by her mother; this completes and confirms the previous two acts of violence that occurred (Jefferson, 1990) All three violent acts imply a sense of force from the mother to the child, and is confirmed on line 295, "she made me do things". This is followed by a consensus warrant "y'know" (Line 295) in an attempt for agreement or understanding from the interviewer, which in turn gains permission to avoid describing the abuse; displaying the difficulty of topic.

Category entitlement of mother assumes mothers to be selfless, however this is contradicted by Sara giving a selfish account for her mother's abuse "for her satisfaction" 
(Line 296). The vocal emphasis on "her" (Line 296) implies sole satisfaction, thus contradicting society's social construction of the category mother which embodies selflessness and, in some respects, a nonsexual being.

\section{Discussion}

This paper has examined child sexual abuse committed by females. A discursive approach highlights how constructions of women through language contributes to the difficulties in comprehending behaviour displayed by women who do not conform to our expected behaviours. Within language use, CBAs for women highlights society's expected behaviour and characteristics for this group, and when two categories such as woman and abuser are combined, conflicting and contradictory behaviour and characteristics are merged, creating unsettling feelings. The findings show that three main constructions of women were found in the language from people with lived experience of sexual abuse by females: women can be trusted, women do not manipulate and groom, and women are not sexually aggressive. When these constructions are challenged, comprehending the reality is difficult to accept and the verbal creation of their accounts reveals heightened negative reactions to towards these women who challenge the expected gender category and associated conducts.

It was demonstrated here that opposing CBAs to that of mother and woman is regularly viewed as a betrayal to the female sex. This in turn led to the view of an 'unnatural' quality to women who abuse children, concluding that females who commit sexual offences against children's must be 'mentally ill' or 'evil' as they do not represent a 'true' portrayal 
of women. These findings mirror previous work which suggests sexually promiscuous women are prone to societal rejection (Jewkes, 2004). A further reaction to female child sex offenders is to attempt to explain these women's actions in a way that distances females who sexually abuse children, from females who do not (Saradijian, 1996). Analysis here showed that women who commit sexual offences against children are re-constructed as a monster who sought possession of the children to fulfil their illicit desires.

The findings here have demonstrated how CBAs are linked with society's expected behaviour for females making child abuse committed by women hard to accept Consequences of constructing women in this way may include, that children who accuse women of these offences are less likely to be believed, as women have been constructed as being incapable of such acts or as being coerced by males to engage in such acts (Robertiello and Terry, 2007). This is supported by literature that suggests that a proportion of society may be oblivious to the existence of female child sex abusers (Bunting, 2005; Denov, 2003a, 2003b, 2004a; Krug, 1989) and that professionals in the area are often in denial about sexual abuse committed by females (Bunting, 2005). This can result in difficulties in the abuse being reported and ultimately believed. This assumption that only men abuse, can also lead to female child sex abuse being underreported (Cortoni et al., 2017; Lawson, 1993). Such underreporting reflects society's reluctance to acknowledge female child sex abuse, as the CBA's associated with women are so entrenched within our constructions of gender. Therefore, it is of benefit to society and future victims to encourage the awareness of female sexual abuse against children. 
It is important to acknowledge prominent use of gender categories throughout discourse, to broaden knowledge in how the social construction of gender influences anticipated gender roles and creates expectations in society for both males and females. As a result, when women commit an offence that is often committed by men, it is often perceived to be a worse form of abuse and contradicts previous literature that suggests female sex abuse of children is of little significance (Mathis, 1972). More realistic and diverse category bound activities (CBAs) of females, would promote both the positive and negative capabilities of women. The current research may contribute to the acceptance of 'equal' CBA ranges for both men and women, whereby a wider knowledge of the existence of such abuse may result in authenticating children's claims.

It is unfortunate that so many female sex offenders and their victims are reluctant to discuss their experiences, which illustrates the stigma and stain attached to these offences because of how gender is constructed. Being unable to explore the narratives of victims of sexual offences committed by women, alongside the limited access to such data at this level, makes it difficult to conduct research in this area rendering it necessary to use secondary data in this study. However, the lived experiences of the people included in this analysis provide crucial insight into the experiences of child sexual abuse committed by females and has highlighted the need for further research in this area.

Through the accounts seen here it has been illustrated how gender is constructed and understood through language and discourse. The findings highlight that society's constructions and assumptions of gender regarding women are inaccurate. It is crucial, for the sake of past, current and future victims of female abuse, that the perceptions of women's 
capabilities is altered, to ensure that victims narratives, however uncomfortable to hear, are understood and believed.

\title{
References
}

\begin{abstract}
Atkinson, M. and Heritage, J. (1984), The Structure of Social Action. Cambridge: Cambridge University Press.
\end{abstract}

Banning, A. (1989), "Mother and Son Incest; Confronting a Prejudice". Child Abuse and Neglect, Vol. 13 No. 4, pp. 563-570. doi: 10.1016/0145-2134(89)90060-4

Baker, C.D. (2000), "Locating Culture in Action: Membership Categorization in Texts and Talk”. In A. Lee and C. Poynton (Eds), Culture and Text: Discourse and Methodology in Social Research and Cultural Studies, London: Routledge, pp. 99-113.

Berliner, L. (2018), “The Concept of Grooming and How It Can Help Victims”. Journal of Interpersonal Violence, 33(1), 24-27. doi: 10.1177/0886260517742057

Birch, H. (1993), "If Looks Could Kill". In H. Birch (Eds), Moving Targets; Women, Murder and Representation. Los Angeles; University of California Press, pp. 32-61.

Bunting, L. (2005), Females Who Sexually Offend Against Children; Responses of the Child Protection and Criminal Justice Systems. London; NSPCC.

Cortoni, F., Babchishin, K.M., and Rat, C. (2017), "The Proportion of Sexual Offenders Who Are Female Is Higher Than Thought". Criminal Justice and Behaviour, Vol. 44, No. 2, pp. 145-162. doi: 10.1177/0093854816658923 
Cortoni, F. and Hanson, R. K. (2005), A Review of the Recidivism Rates of Adult Female Sexual Offenders. Ontario; Canada Correctional Services.

Cortoni, F., Hanson, R. K. and Coache, M. E. (2010), "The recidivism rates of female sexual offenders are low: A meta-analysis". Sexual Abuse: A Journal of Research and Treatment, Vol. 22 No. 1, pp. 387-401. doi: 10.1177/1079063210372142

Denov, M. S. (2004a), Perspectives on Female Sexual Offending; A Culture of Denial. Aldershot; Ashgate.

Denov, M. S. (2004b), “The Long-Term Effects of Child Sexual Abuse by Female Perpetrators: A Qualitative Study of Male and Female Victims”. Journal of Interpersonal Violence, Vol. 19, No. 10, pp. 1137-1156. doi: 10.1177/0886260504269093

Denov, M. (2003a), "To a safer place? Victims of sexual abuse by females and their disclosures to professionals". Child Abuse and Neglect, Vol. 27, No. 1, pp. 47-61. doi: $10.1016 / \mathrm{S} 0145-2134(02) 00509-4$

Denov, M. (2003b). "The myth of innocence: Sexual scripts and the recognition of child sexual abuse by female perpetrators". Journal of Sex Research, Vol. 40, No. 3, pp. 303315.

Edwards, D. and Potter, J. (1992), Discursive Psychology. London: Sage.

Finkelhor, D. (1984), Child Sexual Abuse: New Theory and Research. New York; Free Press.

Finkelhor. D. and Russell, D. (1984), “Women as perpetrators: review of the evidence”. In D. Finkelhor (Eds.), Child Sexual Abuse: New Theory and Research. New York: FreePress. 
Hester, S. and Eglin, P. (1997), Culture in Action: Studies in Membership Categorisation Analysis. Maryland: University Press of America.

Hetherton, J. (1999), "The idealization of women: Its role in the minimization of child sexual abuse by females", Child Abuse and Neglect, Vol. 23, No. 2, pp. 161-174. doi: 10.1016/S0145-2134(98)00119-7

Jefferson, G, C. (1990). "List construction as a task and an interactional resource". In G. Psathos (Eds.), Interactional Competence. Lanham: University press of America, pp. 6392

Jewkes, Y. (2004), Media and Crime. London; Sage.

Kemshall, H. (2004), Risk, Dangerousness and Female Offenders. In G. McIvor (Eds) Women Who Offend, New York; Jessica Kingsley, pp. 209-116.

Krista, A. (1994), Deadlier than the male: Violence and aggression in women. London, England: Harper Collins.

Krug, R. S. (1989), “Adult male report of childhood sexual abuse by mothers. Case descriptions, motivations, and long-term consequences". Child Abuse and Neglect, Vol. 13, No. 1, pp. 111-119. doi:10.1016/0145-2134(89)90034-3

Lawson, C. (1991), "Clinical assessment of mother and son sexual abuse”. Clinical Social Work Journal, Vol. 19, No. 4, pp. 391-403. doi: 10.1007/BF00757441

Lepper, G. (2000), Categories in Text and Talk. London: Sage.

Lorber, J (1994), Paradoxes of Gender. New York: Yale University. 


\begin{abstract}
Makitalo, A. and Saljo, R. (2002), Talk in Institutional Context and Institutional Context in Talk. Categories as Situated Practice, Vol. 22, No. 1, pp. 57-82. doi: $10.1515 /$ text.2002.005
\end{abstract}

Mathis, J. L. (1972), Clear Thinking About Sexual Deviation. Chicago: Nelson Hall.

Mayer, A. (1992), Women Sex Offenders; Treatment and Dynamics. Holmes Beach, Florida; Learning Publications.

Molloy, P. (Director). (1997, October 6). The Ultimate Taboo [Documentary series episode] In S. Hewlett (Producer), Panorama. London: British Broadcasting Corporation (BBC)

Nilan, P. (1995), "Membership Categorization Devices UInder Construction: Social Identity Boundary Maintenance in Everyday Discourse", Australian Review of Applied Linguistics, Vol. 18, No. 1, pp. 69-94. doi: 10.1075/aral.18.1.05nil

Robertiello, G. and Terry, K. (2007). "Can we profile sex offenders? A review of sex offender typologies". Aggression and violent behaviour, Vol. 12, No. 5, pp. 508-518. doi: 10.1016/j.avb.2007.02.010

Sacks, H. (1972). “On the Analyzability of Stories by Children”. In J.J. Gumperz and D. Hymes (Eds), Directions in Sociolinguistics: The Ethnography of Communication. New York: Rinehart and Winston, pp. 325-345.

Sacks, H. (1995), Lectures on Conversation. Oxford: Blackwell.

Saradjian, J. (1996), Women Who Sexually Abuse Children; From Research to Clinical Practice. Chichester; John Wiley and Sons.

Scheloff, E. A. (1992), “Harvey Sacks - Lectures 1964-65: An introduction/ Memoir”. Human Studies, Vol. 12, No. 1, pp. 185-209. doi: 10.1007/BF00142761 
Silverman, D. (2001), Interpreting Qualitative Data: methods for Analysing Talk, Text and Interaction. London: Sage.

Silverman, D. (1998), Harvey Sacks: social science and conversational analysis. London: Sage

Smith, D.E. (1987), The Everyday World as Problematic: A Feminist Sociology. Boston: Northeastern University.

Stanley, L. and Wise, S. (1993), Breaking out again: Feminist Ontology and Epistemology. London: Routledge.

Stokoe, E. H (2003), "Mothers, Single Women and Sluts: Gender, Morality and Membership Categorization in Neighbour Disputes". Feminism Psychology, Vol. 13, pp. 317-344. doi: 10.1177/0959353503013003006

Taino, L. (2002), "Negotiating Gender Identities and Sexual Agency in Elderly Couples' Talk”. In P. Mcllvenny (Eds.) Talking Gender and Sexuality: Conversation, Performativity and Discourse in Interaction. Amsterdam: John Benjamins, pp. 181-206.

Tajfel, H. and Turner, J. (1979). "An integrative theory of intergroup conflict". In M. Wetherell (Eds.) Identities, Groups and Social Issues. London: Sage, pp. 78-91.

Toro-Morn M.I. (2008), "Beyond Gender Dichotomies: Toward a New Century of Gendered Scholarship in the Latina/o Experience”. In: Rodríguez H., Sáenz R., Menjívar C. (eds) Latinas/os in the United States: Changing the Face of América. Springer, Boston, MA, pp. 227-268.

Tsopelas, C., Tsetsou, S., Ntounas, P., and Douzenis, A. (2012). Female perpetrators of sexual abuse of minors: What are the consequences for the victims? International Journal of law and Psychiatry, Vol. 25, No. 1, pp. 305-310. doi: 10.1016/j.ijlp.2012.04.003 
Turner, J. C., Hogg, M. A., Oakes, P. J., Reicher, S. D., and Wetherell, M. (1987), Rediscovering the social group: A self-categorization theory. Oxford, England: Basil Blackwell.

Wahl, C.W. (1960), The psychodynamics of consummated maternal incest. Archives of General Psychiatry, Vol. 3, No. 1, pp. 188-193. doi: 10.1001/archpsyc.1960.01710020072009

Watson, R. (1997), “Some General Reflections on 'Categorization' and 'Sequence' in the Analysis of Conversation". In S. Hester and P. Eglin (Eds) Culture in Action: Membership Categorization Analysis, Boston: International Institute for Ethnomethodology and University Press of America, pp. 49-75.

Watson, R. and Weinberg, T. (1982), Interviews and the Interactional Construction of Accounts of Homosexual Identity, Social Analysis, Vol. 11, No. 1, pp. 56-78.

West, C. and Zimmerman, D.H. (1987), "Doing gender”, Gender and Society, Vol. 1, No. 1, pp. 125-151. doi: 10.1177/0891243287001002002

Widdicombe, S. and Woofitt, R. (1995), The Language of Youth Subcultures. Hemel Hempstead: Harvester Wheatsheaf.

Williams, R., Gillespie, S.M. and Elliot, I.A. (2019), "Characteristics of Female Solo and Female Co-Offenders and Male Solo Sexual Offenders Against Children”. Sexual Abuse, Vol. 31, No. 2, pp. 151-172. doi: 10.1177/1079063217724767

Wowk, M. T. (1984), "Blame Allocation, Sex and Gender in a Murder Interrogation”, Women's Studies International Forum, Vol. 7, No. 1, pp. 75-82. doi: 10.1016/02775395(84)90087-6 
Wykes, M. (1998), “A Family Affair: The British Press, Sex and the Wests”. In Carter, C., Branston, G. and Allen, S. (Eds) News, Gender and Power. London; Routledge, pp. 233247. 
Transcription Key

(adapted by authors, taken from Jefferson in Atkinson and Heritage, 1984)

\begin{tabular}{|l|l|}
\hline Transcription Symbol & Connotation \\
\hline$(0.2)$ & $\begin{array}{l}\text { Brackets around numbers measures speech } \\
\text { pauses in seconds or tenths of a second }\end{array}$ \\
\hline$()$. & Micropause in speech \\
\hline$>$ text $<$ & Latches successive talk for one speaker only \\
\hline Underlining & Vocal emphasis on speech \\
\hline$\uparrow$ got & Sudden increase in tone \\
\hline$\downarrow$ trust & Sudden decrease in tone \\
\hline hhh & Outbreath in speech \\
\hline .hhh & Intake of breath in speech \\
\hline Be:lie:ve & Elongation of speech \\
\hline cha(h)nce & Indicates laughing within speech \\
\hline$(($ transcriber comment $))$ & $\begin{array}{l}\text { Additional comments from the transcriber to } \\
\text { add context }\end{array}$ \\
\hline $\begin{array}{l}\text { o escape } \\
\text { (t) }\end{array}$ & Quieter speech \\
\hline $\begin{array}{l}\text { Dominant partner? }= \\
=\text { my mother }\end{array}$ & Successive latching for two speakers \\
\hline
\end{tabular}

